The Journal of

THORACIC

AND

\title{
CARDIOVASCULAR SURGERY
}

\section{SURGERY FOR ACQUIRED HEART DISEASE}

\section{TRANSMYOCARDIAL LASER TREATMENT DENERVATES CANINE MYOCARDIUM}

King F. Kwong, $\mathrm{MD}^{\mathrm{a}}$

Georgios K. Kanellopoulos, $\mathrm{MD}^{\mathrm{a}}$

Joshua C. Nickols ${ }^{b}$

Steven M. Pogwizd, MD

Jeffrey E. Saffitz, MD, $\mathrm{PhD}^{\mathrm{c}}$

Richard B. Schuessler, PhD

Thoralf M. Sundt III, MD
Background: In patients with refractory angina who are not candidates for conventional revascularization, transmyocardial laser treatment reduces angina significantly in the early postoperative period. We hypothesized that transmyocardial laser treatment damages cardiac nerve fibers that convey the pain of angina pectoris. Methods: Left thoracotomy was performed in sixteen adult mongrel dogs. Treatment groups included animals in which a portion of the left ventricle underwent creation of transmyocardial channels with a holmium:yttrium-aluminum-garnet laser $(n=5)$ or chemical destruction of cardiac nerves by application of phenol to the epicardium $(n=5)$. Sham-operated negative control animals underwent thoracotomy and pericardiotomy alone $(n=6)$. Cardiac afferent nerve function was assessed by epicardial application of bradykinin, a potent algesic, before treatment and 2 weeks after the operation. The resulting central nervous system-mediated decrease in systemic mean arterial pressure was measured. Cardiac innervation of treated and untreated 'left ventricular myocardium was further assessed by immunoblot analysis performed with an antibody against tyrosine hydroxylase, a sympathetic nerve-specific enzyme. Results: Before treatment, changes in systemic arterial pressure were seen with bradykinin stimulation in all dogs. Two weeks after
From the Division of Cardiothoracic Surgery, Department of Surgery, ${ }^{\mathrm{a}}$ Division of Cardiology, ${ }^{\mathrm{b}}$ and the Department of Pathology, ${ }^{\mathrm{c}}$ Washington University School of Medicine, St. Louis, Mo.

Supported in part by a grant from CardioGenesis Corp., Sunnyvale, Calif.

Read at the Seventy-seventh Annual Meeting of The American Association for Thoracic Surgery, Washington, D.C., May 4-7, 1997.

Received for publication May 6, 1997; revisions requested July 7, 1997; revisions received August 12, 1997; accepted for publication August 14, 1997.
Address for reprints: Thoralf M. Sundt III, MD, Division of Cardiothoracic Surgery, Washington University School of Medicine, Queeny Tower, Suite 3108, One Barnes Hospital Plaza, St. Louis, MO 63110.

J Thorac Cardiovasc Surg 1997;114:883-90

Copyright 으 1997 by Mosby-Year Book, Inc.

$0022-5223 / 97 \$ 5.00+0 \quad \mathbf{1 2 / 6 / 8 5 5 3 5}$ 


\begin{abstract}
treatment, no hemodynamic response was seen after stimulation of laser- or phenol-treated areas, but a normal response was seen after stimulation of untreated areas in these same animals and in negative control animals. Immunoblots demonstrated loss of tyrosine hydroxylase in regions of phenol and laser treatment. Conclusion: Transmyocardial laser treatment destroys cardiac nerve fibers, which may contribute to the reduced angina pectoris seen clinically. ( $J$ Thorac Cardiovasc Surg 1997;114:883-90)
\end{abstract}

$\mathrm{E}_{\mathrm{m}}^{\mathrm{a}}$ arly attempts at indirect revascularization of the myocardium included Beck's pedicle procedure ${ }^{1}$ and Vineberg's internal thoracic artery implantation procedures. ${ }^{2,3}$ With the successful development of cardiopulmonary bypass and the more effective method of direct coronary revascularization, indirect approaches were largely abandoned. Recent advances in laser technology, coupled with the need to find treatment options for an increasing number of patients with refractory angina who are not candidates for conventional angioplasty or coronary artery bypass grafting, have renewed interest in indirect approaches to myocardial revascularization.

Transmyocardial laser treatment is one such indirect approach. Some have proposed that it revascularizes the myocardium by augmenting myocardial perfusion through laser-created channels. The patency of these channels, however, is a topic of continuing controversy. Mirhoseini and Cayton ${ }^{4}$ reported the first use of transmyocardial laser treatment in a canine model, arguing that laser energy would induce minimal scar tissue formation and result in patent endothelialized conduits for blood flow between the ventricular chamber and the ischemic myocardium. Hardy and colleagues, ${ }^{5}$ however, demonstrated that the common outcome of lasercreated channels was occlusion, and that patency was at best a transient feature. Despite limited histologic analysis in patients, some investigators have provided support for persistent channel paten$\mathrm{cy},{ }^{6}$ whereas others have found evidence for early channel occlusion. ${ }^{7-9}$

A second proposed mechanism of transmyocardial laser treatment is angiogenesis, but data showing improvements in regional myocardial perfusion have been inconsistent. ${ }^{10-13}$ As well, conclusive evidence for angiogenesis after transmyocardial laser treatment has not been found in animal studies. ${ }^{5,8}$

Although the exact therapeutic mechanism remains to be determined, one consistent finding from the clinical data has been the improvement in angina class rankings of patients after transmyocardial laser treatment. ${ }^{10-13}$ One possible explanation for angina relief after laser treatment is denervation of the myocardium. Laser-induced myocardial injury is nonspecific, and damage occurs to all tissue components of the myocardium, including the nerves that innervate the heart. Although attention has been focused on increased perfusion by laser treatment, denervation of the myocardium as a potential contributing factor to angina relief has not been examined previously. The objective of this study was to determine whether cardiac afferent fibers, which convey the pain of angina pectoris, are damaged by transmyocardial laser treatment.

\section{Methods}

Surgical model. Adult mongrel dogs weighing approximately $25 \mathrm{~kg}$ were intravenously sedated with $25 \mathrm{mg} / \mathrm{kg}$ sodium thiopental, endotracheally intubated, ventilated, and maintained under general anesthesia with continuously administered $1.25 \%$ isoflurane. During the operation and in the perioperative period, surface electrocardiogram, oxygen saturation, and arterial blood pressure were monitored. Left thoracotomy and pericardiotomy were performed to expose the anterior left ventricle. As shown in Fig. 1, $A$, three specific anatomic regions of the anterior left ventricle were designated in the following manner: an area adjacent to the atrioventricular groove (region 1), a middle area bounded by two major diagonal branches of the left anterior descending coronary artery (region 2), and the left ventricular portion of the apex of the heart (region 3). The temperature of the heart was monitored and maintained between $36^{\circ}$ and $38^{\circ} \mathrm{C}$ by periodic irrigation of the thoracic cavity with warm normal saline solution.

Stimulation of cardiac visceral afferents by topical epicardial application of bradykinin was performed, followed by either laser treatment of the myocardium or application of phenol to the epicardium. Animals in the negative control (sham operation) group did not undergo this additional intervention. The pericardium was then loosely reapproximated, the thoracotomy was closed, and the animal was awakened from anesthesia. Another thoracotomy was performed in similar fashion 2 weeks after the first operation, and the functional status of the cardiac visceral afferent fibers was again tested with bradykinin. 
Sham

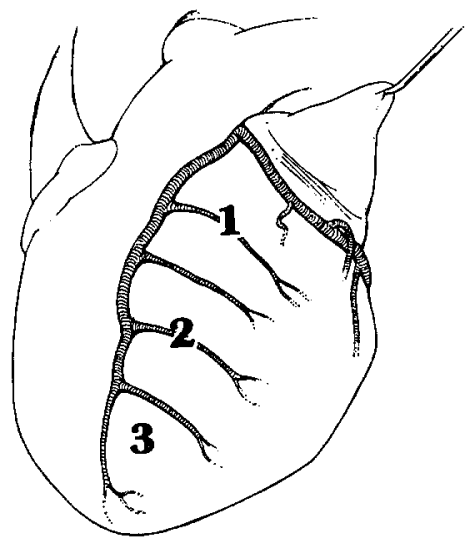

$(\mathrm{n}=6)$
Laser

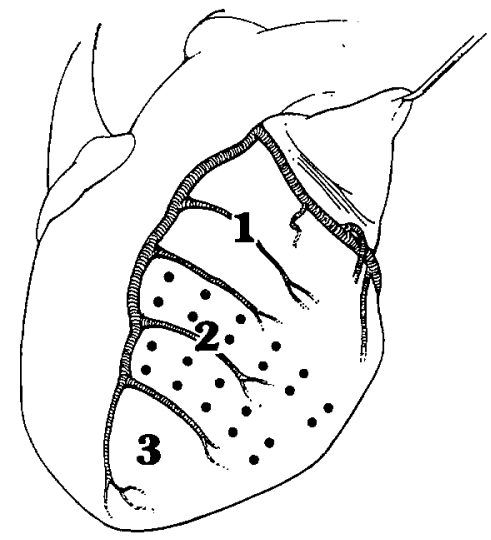

$(n=5)$
Phenol

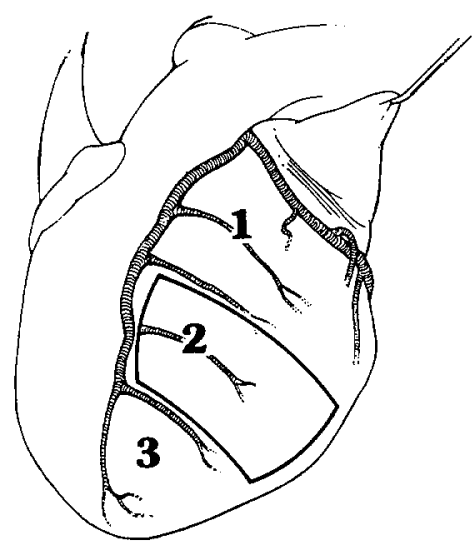

$(n=5)$

Fig. 1. Designated left ventricular myocardial regions in sham-operated (A), laser-treated (B), and phenol-treated $(\mathbf{C})$ canine hearts.

All dogs received humane care in accordance with the "Principles of Laboratory Animal Care" formulated by the National Society for Medical Research and the "Guide for the Care and Use of Laboratory Animals" prepared by the Institute of Laboratory Animal Resources and published by the National Institutes of Health (NIH Publication No. 85-23, revised 1985).

Stimulation of cardiac visceral afferent nerves. Cardiac afferent nerves were assessed functionally by stimulation with topical epicardial application of bradykinin $(300 \mu \mathrm{g}$ in $150 \mu \mathrm{l}$ saline solution per stimulation) in each of the three designated left ventricular regions. The bradykinin was kept in a water bath at $36^{\circ} \mathrm{C}$ and delivered onto a $1 \times$ $1 \mathrm{~cm}$ gauze placed in the center of the myocardial region of interest. ${ }^{14-16}$ Arterial blood pressure, mean arterial pressure (MAP), and surface electrocardiogram were recorded during bradykinin stimulation. The bradykininsoaked gauze was removed after 2 minutes, and the excess bradykinin was washed away with normal saline solution. Each of the three myocardial regions was stimulated again at the second thoracotomy. A decrease greater than $5 \mathrm{~mm}$ $\mathrm{Hg}$ from baseline MAP was considered to represent a response to bradykinin stimulation. If no response to bradykinin stimulation was found in a particular region of the myocardium at the second thoracotomy, two additional attempts were performed within the same treatment region to confirm the lack of response. Topical bradykinin was also applied to the exposed surface of the latissimus dorsi muscle, as seen in the thoracotomy operative field, to demonstrate that topical bradykinin was not diffusing into the circulation and causing the observed changes in blood pressure.

Treatment groups. Region 2 of the anterior left ventricle underwent either transmyocardial laser procedure $(n=5)$, topical phenol application $(n=5)$, or no treatment $(n=6)$. Laser channels were created with a pulsed holmium:yttrium-aluminum-garnet (Ho:YAG) laser $(\lambda=2.1 \mu \mathrm{m}$; CardioGenesis Corp., Sunnyvale, Calif.). As shown in Fig. 1, $B$, laser holes, spaced approximately 1 $\mathrm{cm}$ apart, were drilled along side the diagonal vessels and within the bounded treatment region. Immediately after channel creation, hemostasis was achieved with digital pressure. Between 18 and 26 transmyocardial laser channels per heart were created in region 2 (mean number, 22). Laser energy was delivered to the myocardium in bursts of 3 pulses ( $2 \mathrm{~J} /$ pulse), timed to the $R$ wave of the electrocardiogram. On average, five bursts (30 J) were required to create a transmyocardial channel. As shown in Fig. 1, $C$, sympathetic denervation was chemically induced by topical application of $85 \%$ phenol to the epicardial surface by painting the perimeter of the treatment region with a cotton-tipped applicator stick. ${ }^{15}$ The negative control group received only sham operation.

Immunoblotting. Changes in cardiac innervation at 2 weeks after treatment were assessed by immunoblot analysis of treated and untreated myocardial tissue from nine randomly selected animals (three from each treatment group) for tyrosine hydroxylase, an enzyme specific to sympathetic nerves. For each region of left ventricular myocardium sampled, approximately $500 \mathrm{mg}$ frozen, unfixed, full-thickness tissue was excised from the center of the treatment region. The tissue samples were homogenized with cold homogenization buffer $(20 \mathrm{mmol} / \mathrm{L}$ tris(hydroxymethyl)aminomethane hydrochloride [Tris$\mathrm{HCl}$, $1 \mathrm{mmol} / \mathrm{L}$ ethyleneglycol-bis[ $\beta$-aminoethylether]$\mathrm{N}, \mathrm{N}, \mathrm{N}^{\prime}, \mathrm{N}^{\prime}$-tetraacetic acid [EGTA], $5 \mathrm{mmol} / \mathrm{L}$ sodium azide, $50 \mathrm{mmol} / \mathrm{L}$ sodium chloride, $10 \mathrm{mmol} / \mathrm{L} \beta$-mercapto-ethanol, and phenylmethylsulfonyl $2 \mathrm{mmol} / \mathrm{L}$ fluoride, $\mathrm{pH} \mathrm{7.4)}$ and then centrifuged at $10,000 \mathrm{rpm}$ for 30 minutes at $4^{\circ} \mathrm{C}$. Electrophoresis buffer $(200 \mu \mathrm{l} ; 125$ $\mathrm{mmol} / \mathrm{L}$ Tris- $\mathrm{HCl}, 1 \mathrm{mmol} / \mathrm{L}$ EGTA, $2 \%$ sodium dodecyl sulfate, $10 \mathrm{mmol} / \mathrm{L} \beta$-mercapto-ethanol, and $2 \mathrm{mmol} / \mathrm{L}$ 

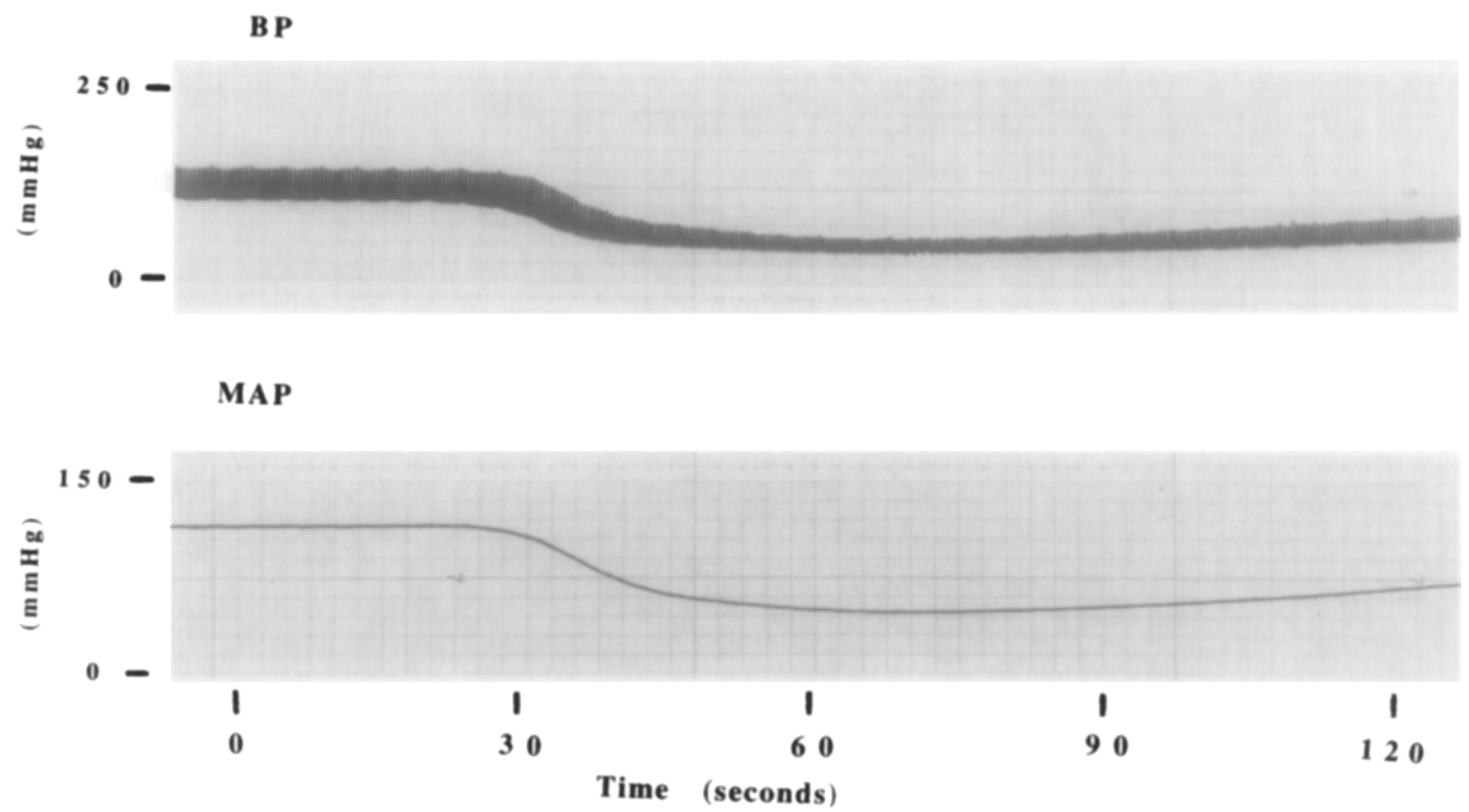

Fig. 2. Typical blood pressure $(B P)$ and MAP recordings during topical epicardial bradykinin stimulation in region 2 before treatment.

phenylmethylsulfonyl fluoride, $\mathrm{pH} 6.8$ ) was added to the supernatant and the mixture was sonicated. Equivalent amounts of protein from each tissue sample, as determined by Bradford assay (Bio-Rad Chemicals, Richmond, Calif.), were loaded onto a $12.5 \%$ polyacrylamide gel. Molecular weight marker standards were also applied to each gel (Amersham Life Sciences, Arlington Heights, III.).

The proteins resolved by sodium dodecyl sulfate-polyacrylamide gel electrophoresis were transferred onto a nitrocellulose blot with a semidry transfer apparatus, and the accuracy of protein transfer was verified by Coomassie blue staining of the gel. The blots were blocked in $2 \%$ gelatin-phosphate buffered saline solution (PBS) overnight at $25^{\circ} \mathrm{C}$. Blots were then incubated with a mouse monoclonal immunoglobulin $\mathrm{G}$ antibody monospecific for tyrosine hydroxylase (1:1000; Chemicon International Inc., Temecula, Calif.) for 3 hours at $25^{\circ} \mathrm{C}$. After the blots were washed with $0.5 \%$ polyoxyethylene ether (Triton)PBS, horseradish peroxidase-conjugated donkey antimouse immunoglobulin $\mathrm{G}$ antibody at a 1:10,000 dilution was applied (Jackson ImmunoResearch, West Grove, Pa.) and blots were incubated for 1.5 hours at $25^{\circ} \mathrm{C}$. The blots were washed again with Triton-PBS, developed with the enhanced chemiluminescence system (Amersham Life Sciences), and then exposed to x-ray film.

Data analysis. All data from bradykinin stimulation were reported as mean \pm standard deviation and analyzed with the SYSTAT system for statistics (SPSS, Inc., Chicago, Ill.). Repeated-measures analyses of variance with two group factors, the region of the heart and the treatment, were used to compare the percentage change in MAP during bradykinin stimulation before treatment and at 2 weeks after treatment. Contrast was used to compare the before-treatment response between treatment groups. A $p$ value less than 0.05 was considered significant.

\section{Results}

Surgical procedure. There were no operative deaths, and no animals were excluded. Regional wall motion appeared grossly unchanged immediately after laser treatment or phenol application.

Stimulation of cardiac pain fibers. Fig. 2 shows a typical blood pressure recording in response to bradykinin stimulation before phenol or laser treatment. In our analysis of the data, we measured the maximal decrease in MAP in response to bradykinin stimulation and represented this decrease as a percentage of the baseline MAP of the animal. There was no difference in pretreatment response between treatment groups for each region $(p>0.5)$. Phenol and laser group animals responded to bradykinin stimulation in all left ventricular areas before phenol application or transmyocardial laser treatment. At 2 weeks after treatment, bradykinin stimulation in the treated left ventricular areas (region 2) of the phenol and laser group animals did not elicit the reflex response; however, untreated atrioventricular groove areas (region 1) in the same animals consistently showed persistence of the bradykinin-evoked reflex response. Region 3 of phenol- and laser- 
Table I. Percentage of bradykinin-evoked decrease from baseline $M A P$

\begin{tabular}{|c|c|c|c|c|c|c|}
\hline & \multicolumn{2}{|c|}{ Region 1} & \multicolumn{2}{|c|}{ Region 2} & \multicolumn{2}{|c|}{ Region 3} \\
\hline & Before & After & Before & After & Before & After \\
\hline Sham & $34 \pm 11$ & $31 \pm 15$ & $22 \pm 9$ & $22 \pm 8$ & $24 \pm 9$ & $23 \pm 5$ \\
\hline Phenol & $39 \pm 9$ & $32 \pm 13$ & $15 \pm 6$ & $2 \pm 2^{*}$ & $16 \pm 15$ & $7 \pm 6^{*}$ \\
\hline Laser & $40 \pm 10$ & $44 \pm 25$ & $23 \pm 8$ & $0 \pm 0^{*}$ & $17 \pm 8$ & $11 \pm 7^{*}$ \\
\hline
\end{tabular}

Values are mean \pm standard deviation; $\mathrm{MAP}$ in $\mathrm{mm} \mathrm{Hg}$.

* $p<0.001$ (before vs after treatment).

treated animals displayed an attenuated but variable response to bradykinin stimulation. The negative control group consistently showed responses to bradykinin stimulation in all left ventricular regions. Topical application of bradykinin to the surface of the latissimus dorsi muscle did not produce any hemodynamic changes (data not shown). Table I summarizes the bradykinin-evoked response data from the three treatment groups in numeric format. Heart rate did not appear to be affected by transient application of bradykinin.

Immunoblotting. Fig. 3 shows a representative immunoblot. A $62 \mathrm{kd}$ band, corresponding to the presence of tyrosine hydroxylase, ${ }^{17,18}$ was identified in the untreated tissue (region 1) in both the phenol and laser groups. In contrast, it was significantly attenuated in phenol-treated myocardium and entirely absent in laser-treated myocardium. The $62 \mathrm{kd}$ band was present in tissues from regions 1,2 , and 3 in all negative control animals. All animals in a particular treatment group produced the same pattern of tyrosine hydroxylase immunoreactivity in regions 1 and 2 of the left ventricular myocardium. A $62 \mathrm{kd}$ band was variably present in region 3 of phenol and laser group animals.

\section{Discussion}

In this study, we demonstrated in a canine model that a neural-specific enzyme, as well as the function of cardiac nerves on the end-organ level, is lost as a result of transmyocardial laser treatment. Clinical studies have shown that most patients have a significant decrease in angina after undergoing transmyocardial laser treatment. ${ }^{11-13}$ Our data implicate denervation as one possible mechanism for this angina relief.

Cardiac innervation in the canine model has been extensively investigated ${ }^{19,20}$ and roughly parallels that found anatomically in humans. In the dog, cardiac sympathetic efferent nerves traverse the subepicardial portion of the myocardium, giving off

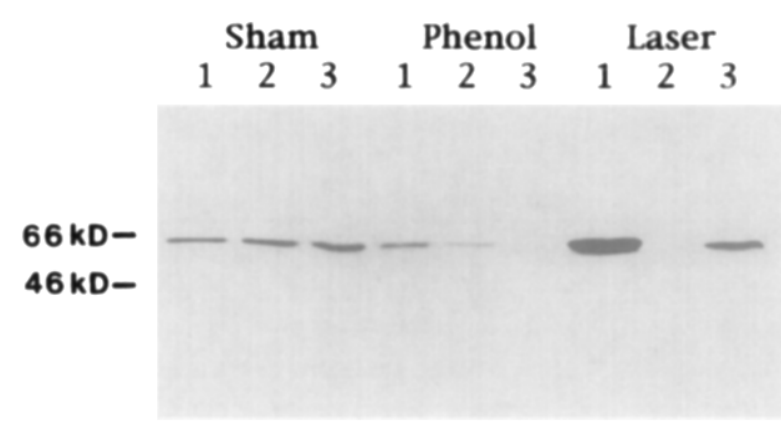

Fig. 3. Representative immunoblot showing loss of tyrosine hydroxylase in treated myocardium (region 2) of phenol- and laser-treated animals. Persistence of tyrosine hydroxylase in region 3 of the laser-treated animal reflects anterior and posterior contributions to the innervation in the cardiac apex. Numbers correspond to treatment regions of the heart depicted in Fig. 1.

deeper branches that extend towards the subendocardium. Cardiac visceral afferent nerve fibers, which convey the pain of angina, are thought to travel alongside the cardiac sympathetic efferents en route to the central nervous system. ${ }^{21}$

The algesic property of bradykinin and the anatomy of the nerves innervating the heart provide a means of assessing the presence of functional afferent pain fibers. Topically applied bradykinin stimulates subepicardial visceral afferents ${ }^{14}$; the resulting bradykinin-evoked cardiovascular response, which was measured in our study, is a result of central nervous system integration of the pain stimulus. The characteristic biphasic reflex response to bradykinin stimulation consists of an initial decrease in MAP from baseline followed by a late, albeit less consistently seen, hypertensive response. ${ }^{14}$ Other investigators have found this late response to be variable from animal to animal and to be affected by the level of anesthesia. ${ }^{15}$ We did not reproducibly observe this component, possibly because of a relatively deep anesthetic plane.

Although it is possible that bradykinin may interact directly with the myocardium, bradykinin receptors have been definitively identified only on vascular smooth muscle cells, fibroblasts, endothelial cells, and neural-derived cells. ${ }^{22}$ Support for the presence of bradykinin receptors has been shown indirectly in neonatal rat cardiac myocyte cell cultures, ${ }^{22}$ but in situ histologic and morphologic characterizations of bradykinin receptors in the heart are still lacking. In our use of bradykinin, and in that of others, ${ }^{15,16}$ only a limited total area of myocardium is briefly exposed to the 
chemical. No significant gross changes in myocardial contraction were observed after this application of bradykinin to the heart. The hemodynamic changes we observed with bradykinin application to the epicardium, which have also been seen by others, are likely the result of cardiac visceral afferent nerve stimulation by bradykinin.

Our positive control animals were treated with topical phenol application, because this has been used previously to denervate the myocardium. ${ }^{15,16}$ After topical application of phenol, the reflex hemodynamic response to bradykinin stimulation was lost in the treated areas. In our study, laser-treated myocardium was similarly unresponsive to bradykinin stimulation, suggesting that denervation had occurred as a result of transmyocardial laser treatment.

In addition to loss of cardiac nerve function, our immunoblot data show that neural-specific elements were also lost as a result of transmyocardial laser treatment. Tyrosine hydroxylase is a sympathetic efferent nerve enzyme involved in the rate-limiting step in the biosynthesis of norepinephrine from tyrosine. ${ }^{23}$ Immunoblot analysis with an antibody monospecific for tyrosine hydroxylase yields a $62 \mathrm{kd}$ protein band. ${ }^{17,18}$ Our immunoblots demonstrate an absence of this neuronally derived protein in laser-treated myocardium. One explanation for this finding is that cardiac nerves are damaged or destroyed as a result of transmyocardial laser treatment, and that the concentration of tyrosine hydroxylase in treated myocardium is diminished in consequence. It seems unlikely that tyrosine hydroxylase, a critical enzyme of functional sympathetic neurons, should be destroyed in isolation as a result of laser injury while sparing the integrity of the neuron itself.

It is noteworthy that the magnitude of response to bradykinin stimulation in the unaltered canine heart was maximal in the ventricular base (region 1) and decreased in the apex (region 3 ). Because the nerves innervating the heart typically travel from a basal to apical direction as they course through the myocardium, their anatomic distribution results in differences in neural density among the different regions of the left ventricle.

Although consistent changes as a result to phenol or laser treatment were seen in region 2 , region 3 of these animals demonstrated variability in both bradykinin-evoked response and tyrosine hydroxylase immunoreactivity. This variability is perhaps a reflection of the dual innervation that the apex (region 3) derives from neural plexuses from both the anterior and posterior regions of the heart. Consequently, the apical region exhibits more variability in indexes representative of innervation. In particular, as shown in Fig. 3, immunoblot analysis of the laser-treated animal demonstrated complete absence of tyrosine hydroxylase in region 2 but a persistence of the enzyme in region 3 . This finding is consistent with an overlap of innervation that can occur in the cardiac apex.

The precise mechanism by which a series of laser channels in myocardium creates regional denervation remains unknown. The laser produces a focused delivery of light energy, but the injury it causes in living tissues is not limited only to the formed channel. Hardy and associates ${ }^{5}$ described histologic zones of injury emanating outward from a central zone of vaporization. Extension of thermal injury beyond the site of direct injury has been detected in normal-appearing cardiomyocytes by observing the loss of naturally occurring birefringence from these cells under polarized light microscopy. ${ }^{24}$ Because laser energy is dissipated mostly as heat, a small degree of subtle thermal damage, undetectable by routine light microscopy, may be occurring in the myocardium adjacent to laser-created channels. Thus the combined tissue destruction and nearby tissue thermal injury from a laser channel may act to interrupt nerves as they course through the myocardium. In our study, we created laser channels $1 \mathrm{~cm}$ apart to parallel the procedure that is currently performed in patients. ${ }^{10-13}$

The results of our study are compatible with denervation of the laser-treated myocardium as a result of interruption of myocardial neural networks. It follows that the density of laser channels, and also possibly the depth of these channels, in the myocardial wall may determine the ultimate extent of denervation resulting from this procedure.

The role of transmyocardial laser treatment in the management of patients with ischemic heart disease continues to evolve. Our data suggest that myocardial denervation as a consequence of laser treatment may contribute to the angina relief that is observed clinically. Although this study in no way rules out concomitant augmented perfusion by any of a variety of mechanisms, it does emphasize the importance of distinguishing clinical angina relief from augmented perfusion and cautions against mistaking improvement in one for evidence of the other. The potential for creating silent ischemia must be considered when evaluating the utility of this therapeutic modality. 
We thank Drs. James L. Cox and John P. Boineau for their support of this work. We also thank Donna Hand, Duane Probst, Dennis Gordon, Bret Cunningham, and Rahkee Kapadia for their perioperative technical support, and Dr. Michael Beardslee for his technical advice on immunoblotting.

\section{REFERENCES}

1. Beck CS. The development of a new blood supply to the heart by operation. Ann Surg 1935;102:801-13.

2. Vineberg AM. Clinical and experimental studies in the treatment of coronary artery insufficiency by internal mammary artery implant. J Int Coll Surg 1954;22:503-18.

3. Vineberg AM. Development of an anastomosis between the coronary vessels and a transplanted internal mammary artery. Can Med Assoc J 1946;55:117-9.

4. Mirhoseini M, Cayton M. Revascularization of the heart by laser. J Microsurg 1981;2:253-60.

5. Hardy RI, Bove KE, James FW, Kaplan S, Goldman L. A histologic study of laser-induced transmyocardial channels. Lasers Surg Med 1987;6:563-73.

6. Cooley DA, Frazier OH, Kadipasaoglu KA, Pehlivanoglu S, Shannon RL, Angelini P. Transmyocardial laser revascularization: anatomic evidence of long-term channel patency. Texas Heart Inst J 1994;21:220-4.

7. Burkhoff D, Fisher PE, Apfelbaum M, Kohmoto T, DeRosa $\mathrm{CM}$, Smith CR. Histologic appearance of transmyocardial laser channels after 41/2 weeks. Ann Thorac Surg 1996;61:1532-5.

8. Fleischer KJ, Goldschmidt-Clermont PJ, Fonger JD, Hutchins GM, Hruban RH, Baumgartner WA. One-month histologic response of transmyocardial laser channels with molecular intervention. Ann Thorac Surg 1996;62:1051-8.

9. Gassler N, Wintzer HO, Stubbe HM, Wullbrand A, Helmchen U. Transmyocardial laser revascularization: histological features in human nonresponder myocardium. Circulation 1997;95:371-5.

10. Frazier $\mathrm{OH}$, Cooley DA, Kadipasaoglu KA, Pehlivanoglu S, Lindenmeir $\mathbf{M}$, Barasch $\mathbf{E}$, et al. Myocardial revascularization with laser: preliminary findings. Circulation 1995; 92(suppl):II58-65.

11. Cooley DA, Frazier OH, Kadipasaoglu KA, Lindenmeir MH, Pehlivanoglu S, Kolff JW, et al. Transmyocardial laser revascularization: clinical experience with twelve-month follow-up. J Thorac Cardiovasc Surg 1996;111:791-9.

12. Horvath KA, Mannting F, Cummings N, Shernan SK, Cohn LH. Transmyocardial laser revascularization: operative techniques and clinical results at two years. J Thorac Cardiovasc Surg 1996;111:1047-53.

13. Horvath KA, Cohn LH, Cooley DA, Crew JR, Frazier OH, Griffith BP, et al. Transmyocardial laser revascularization: results of a multicenter trial with transmyocardial laser revascularization used as sole therapy for end-stage coronary artery disease. J Thorac Cardiovasc Surg 1997;113:645-54.

14. Regoli D, Barabe J. Pharmacology of bradykinin and related kinins. Pharmacol Rev 1980;32:1-46.

15. Barber MJ, Mueller TM, Davies BG, Zipes DP. Phenol topically applied to canine left ventricular epicardium interrupts sympathetic but not vagal afferents. Circ Res 1984;55:532-44.

16. Minisi AJ, Thames MD. Distribution of left ventricular sympathetic afferents demonstrated by reflex responses to transmural myocardial ischemia and to intracoronary and epicardial bradykinin. Circulation 1993;87:240-6.
17. Fleming-Jones RM, McFadden PN. A denaturant-insoluble form of tyrosine dydroxylase in $\mathrm{PC} 12$ pheochromocytoma cells. J Protein Chem 1995;14:275-82.

18. Oki $\mathrm{H}$, Inoue $\mathrm{S}$, Makishima $\mathrm{N}$, Takeyama $\mathrm{Y}$, Shiokawa $\mathrm{A}$. Cardiac sympathetic innervation in patients with dilated cardiomyopathy: immunohistochemical study using antityrosine hydroxylase antibody. Jpn Circ J 1994;58:389-94.

19. Armour JA, Randall WC. Functional anatomy of canine cardiac nerves. Acta Anal 1975;91:510-28.

20. White JC, Garrey WE, Atkins JA. Cardiac innervation. Arch Surg 1933;26:765-86

21. White JC. Cardiac pain: anatomic pathways and physiologic mechanisms. Circulation 1957;16:644-55.

22. Minshall RD, Nakamura F, Becker RP, Rabito SF. Characterization of bradykinin $B_{2}$ receptors in adult myocardium and neonatal rat cardiomyocytes. Circ Res 1995;76:773-80.

23. Wooten GF, Coyle JT. Axonal transport of catecholamine synthesizing and metabolizing enzymes. J Neurochem 1973; 20:1361-71

24. Thomsen S, Pierce JA, Cheong WF. Changes in birefringence as markers of thermal damage in tissues. IEEE Trans Biomed Eng 1989;36:1174-9.

\section{Discussion}

Dr. Lawrence H. Cohn (Boston, Mass.). Dr. Buckberg, who was originally scheduled to do this discussion, could not be here and asked me to substitute for him, and I'm happy to do so.

Dr. Kwong, I think your experimental hypothesis was brilliant, and I think your experiments were beautifully carried out. Unfortunately, I disagree with your conclusion.

At the Brigham, we believe because of both clinical and now some long-term chronic ischemic laboratory studies that angiogenesis, not denervation, is the primary mechanism by which this new therapy works. You heard in the previous research presented that increase in perfusion measured by scans across time can be documented by reduction in ischemic segments, and we now have some patients for whom follow-up has lasted longer than 3 years in whom this effect this has persisted.

We've now seen this in a laboratory experiment, done in a 6-month swine model chronic of ischemia. Dr. Ross Reul in our lab has shown significant increases in subendocardial blood flow.

In a 6-month postischemic laser model in the swine, there is a perfusion of subendocardial blood vessels, both small and medium-sized muscular arteries. These were compared with normal control preparations read blindly by pathologists and were significantly increased above control values. I wonder whether you could comment on this observation.

It's also well known that different lasers cause different amounts of tissue damage, and I think it's well known that the Ho:YAG laser does have a substantially increased local tissue injury compared with the carbon dioxide laser used in this and our clinical study. I wonder whether you could comment as to whether that may have been the reason that you got some of your data.

Finally, Dr. Buckberg suggested to me that your theory of mechanism may well be the reason why a lot of these patients who are have terrible symptoms show an immediate cessation in angina that really is quite dramatic in 
many instances. Actually, if long lasting, this would be quite a dangerous theory because it would be like painless ischemia; as people did more exercise in the later postoperative period, this could be actually a dangerous therapy if your theory were to hold true. I wonder whether you could comment on that as well.

Dr. Craig R. Smith (New York, N.Y.). Practically every time I speak about transmyocardial laser treatment, someone asks whether the beneficial effect could be explained by denervation. I've always acknowledged that possibility but haven't known how to answer the question. You are to be congratulated for making a step toward answering this important question.

Just a couple of things I'll comment on. One is that our group at Columbia will soon present and publish a similar study confirming these results. We didn't include a phenol control group, which is a nice feature of your study. We are currently looking at some other ways of producing this same effect, which may come around to answering the question Dr. Cohn just raised about whether this is an effect specific to the Ho:YAG laser.

If we think about other implications of these findings, though, it becomes a little more complicated. How does this differ conceptually from many other things we do? Look at the effect of phenol, for example. I presume phenol acts on the surface, implying that the nerves are on the surface. How does this differ from taking down a lot of epicardial adhesions in a reoperation, using cautery to control epicardial bleeding, placing multiple pacing wires, applying topical hypothermia, and things of that sort that we do in the normal conduct of heart surgery? Do you suppose that these could also produce denervation?

Dr. Kwong. I thank both Dr. Cohn and Dr. Smith for their insightful remarks and questions. Let me take Dr. Cohn's points first.

Dr. Cohn mentioned that there are considerable data to suggest that increased regional perfusion occurs in the area of myocardium that has been lased. Although I do not doubt that, our study is principally directed toward looking at the process of the destruction of cardiac nerves and denervation as one contributing mechanism in angina relief. So our study does not exclude other mechanisms that may coexist as a result of the transmyocardial laser treatment.

Regarding Dr. Cohn's second question, in terms of the varying laser-tissue interactions that may occur as a result of different lasers, I can only speak to the Ho:YAG laser with which our experiments were performed. I do not have any data regarding the carbon dioxide laser, and although one could expect that different laser parameters might cause different degrees of laser-tissue interaction, I cannot comment knowledgeably on that.

With respect to Dr. Cohn's third point, regarding painless ischemia, I think the jury is still out on that. As Dr. Cohn has mentioned, there seems to be evidence from some investigators that angiogenesis may be another mechanism of this transmyocardial laser procedure. But what our data would seem to imply is that the immediate, dramatic angina relief that patients have after this procedure may be somehow mediated by the destruction of the afferent nerves, the $A \delta$ fibers and $C$ fibers that carry the pain sensation of angina.

Dr. Smith, you mentioned that other methods that cardiac surgeons employ may also cause denervation, and I think that's an astute point. In fact, this is not a new topic. Dr. Dwight Harken, in a 1955 article in Circulation, wrote on deepicardialization with $95 \%$ phenol in a dog model and also reported in that same article on a small series of patients in whom there was rapid relief of angina after phenol treatment, but the mortality in follow-up appeared to be unchanged. Drs. Paul Ebert and David Sabiston also commented on some of the results with surgical denervation in an ischemic dog model that showed a reduction in ventricular arrhythmias in the surgically denervated animals.

It's tempting to speculate, as did Drs. Ebert and Sabiston in their 1968 article in the Annals of Surgery, that perhaps a localized sympathectomy may be occurring as a result of denervation. Perhaps some of these flow data that we are seeing in the clinical setting may be related to this. Although our study does not directly address this issue, it is possible that other mechanisms may coexist with denervation as a result of transmyocardial laser treatment.

\section{Availability of Journal back issues}

As a service to our subscribers, copies of back issues of The Journal of Thoracic and Cardiovascular Surgery for the preceding 5 years are maintained and are available for purchase from Mosby at a cost of $\$ 15.00$ per issue until inventory is depleted. The following quantity discounts are available: $25 \%$ off on quantities of 12 to 23, and one third off on quantities of 24 or more. Please write to Mosby-Year Book, Inc., Subscription Services, 11830 Westline Industrial Drive, St. Louis MO 63146-3318, or call 800-453-4351 or 314-453-4351 for information on availability of particular issues. If unavailable from the publisher, photocopies of complete issues may be purchased from UMI, 300 N. Zeeb Rd., Ann Arbor, MI 48106, 313-761-4700. 